\title{
Pharmacokinetics of single dose intravenous propacetamol in neonates: effect of gestational age
}

\author{
K Allegaert, C D Van der Marel, A Debeer, M A L Pluim, R A Van Lingen, C Vanhole, D Tibboel, \\ H Devlieger
}

See end of article for authors' affiliations

.....................

Correspondence to: Dr Allegaert, Neonatal Intensive Care Unit, Department of Paediatrics, University Hospitals, Gasthuisberg, Herestraat 49, B-3000 Leuven, Belgium; karel.allegaer!@ uz.kuleuven.ac.be

Accepted 20 February 2003
Aim: To investigate the pharmacokinetics and pharmacodynamics of single dose propacetamol in preterm and term infants on the first day of life.

Methods: Neonates were stratified by gestational age. Preterm ( $<37$ weeks) and term (37-41 weeks) infants received a single dose of propacetamol in the first 24 hours of life when they had minor, painful procedures or as additional treatment in infants receiving opioids. Blood samples were taken from an arterial line, and pain was evaluated by a multidimensional pain scale. Results were reported as mean (SD). Student's $t$ and Wilcoxon tests were used to compare the groups.

Results: Thirty neonates were included, 10 of which were term infants. Serum half life was 277 (143) minutes in the preterm infants and $172(59)$ minutes in the term infants $(p<0.05)$. Clearance was 0.116 $(0.08)$ litre $/ \mathrm{kg} / \mathrm{h}$ in the preterm infants and $0.170(0.06)$ litre $/ \mathrm{kg} / \mathrm{h}$ in the term infants $(\mathrm{p}<0.05)$. Gestational age correlated with serum half life $(r=-0.46)$. No effect of sex or administration of prenatal steroids was found on the pharmacokinetics of paracetamol. In neonates who only received propacetamol ( $n=15$ ), the level of analgesia seemed to be associated with the therapeutic (>5 mg/l) level.

Conclusions: A correlation was found between gestational age and the serum half life of propacetamol. The maturational trend of clearance and half life in preterm and term neonates is in line with data on the pharmacokinetics of propacetamol beyond the newborn period.
A dequate management of pain in neonates has been a major issue in neonatal care since Anand et al ${ }^{1}$ showed the positive effect of opioids on mortality and morbidity in neonates having cardiac surgery. Although the NOPAIN preliminary trial only documented a non-significant trend in reduction of poor neurological outcome in preterms receiving morphine during ventilation, pre-emptive analgesia in ventilated infants is considered the standard of care in most neonatal units. ${ }^{2-5}$

Pharmacokinetic and pharmacodynamic studies of most drugs prescribed in contemporary neonatal intensive care are still rare or even lacking, leading to common unlicensed and off label drug use. ${ }^{6}$ To a certain extent, this is also true for paracetamol.

Paracetamol ( $N$-acetyl- $p$-aminophenol) is a readily available antipyretic and analgesic agent. Although less potent than opioids, this drug may have fewer side effects. It is the most often prescribed drug for treatment of mild to moderate pain in infants, including neonates. It can be administered by the oral, rectal, or intravenous route.

Intravenous administration of a prodrug may improve prediction of concentration and consequent effect compared with rectal and/or oral formulations, by eliminating the plasma variability caused by absorption kinetics and relative bioavailibity. ${ }^{7-13}$ The combined use of opioids and paracetamol may reduce the need for opioids and reduce the side effects, especially hypoventilation, in neonates. Although some believe that paracetamol is harmless in neonates, there is potential for hepatotoxicity. ${ }^{14}$ Propacetamol is a prodrug of paracetamol which is hydrolysed by plasma esterases after intravenous administration: $1 \mathrm{~g}$ propacetamol liberates $0.5 \mathrm{~g}$ paracetamol if adequate esterase activity is present, in line with the documented cholinesterase activity. ${ }^{10}{ }^{15}$ To document the pharmacokinetics and pharmacodynamics of propacetamol in neonates of different gestational age (GA), we performed a single-dose study in the first 24 hours of life.

\section{PATIENTS AND METHODS}

All neonates admitted within the first 24 hours of life to the neonatal intensive care unit and with an arterial line in place were considered for inclusion if propacetamol was administered. The decision to prescribe propacetamol or any other analgesic was made by the attending neonatologist. Propacetamol was administered when minor, painful procedures were carried out, such as insertion of a peripheral arterial or venous line, insertion of a central venous line, or placement of a chest tube, or as additional treatment in infants receiving opioids. Exclusion criteria were major congenital malformations and severe birth asphyxia (Apgar score $<4$ at five minutes) in line with other studies performed on neonates. The initial dose $(20 \mathrm{mg}$ (10 mg paracetamol $/ \mathrm{kg}$ ) was based on literature data, with the intention to change this dose if interim analysis of the paracetamol levels in the first 15 infants was inadequate (plasma levels $<5 \mathrm{mg} / \mathrm{l}$ within $8-10$ hours of administration). ${ }^{10-13}$ Maternal use of analgesics (besides paracetamol) was not an exclusion criterion in this single-dose pharmacokinetic study.

As part of standard nursing care in the neonatal intensive care unit, a multidimensional pain scale was used to document pain/comfort. With this pain scale (Leuven neonatal pain scale), three different levels can be discriminated: level $1,<4 / 14$ (no pain); level 2, 4-6/14 (mild discomfort); level 3, > 6/14 (pain). ${ }^{16}$ An algorithm is used within the unit to administer and adapt analgesics based on this pain scale. ${ }^{17}$

The number and dose of other analgesics or sedatives prescribed in the first day of life were recorded. Birth weight

Abbreviations: $\mathrm{GA}$, gestational age; $\mathrm{V}_{\mathrm{d}}$, distribution volume; $\mathrm{CL}_{t}$, total body clearance 
was documented on admission to the unit. GA was estimated by routine ultrasound examination before 20 weeks of gestation if available or was based on the last menstrual period of the mother and postnatal physical characteristics.

Propacetamol was administered as a 15 minute infusion to avoid local discomfort. ${ }^{18}$ Blood samples $(0.2 \mathrm{ml})$ were taken from an arterial line 30, 60, 90, 120, 180, 240, and 600 minutes after the start of intravenous administration. The maximum total amount of blood allowed to be collected in a single neonate was $1 \mathrm{ml} / \mathrm{kg}$. After centrifugation, samples were stored at $-20^{\circ} \mathrm{C}$ until analysis. Plasma paracetamol concentrations were determined using fluorescence polarisation immunoassay (Adx system; Abbott Laboratories, North Chicago, IL, USA). The determination limit was $1 \mathrm{mg} / \mathrm{l}$, and the precision was $7 \%$.

Pharmacokinetics were calculated assuming a linear one compartment model with instantaneous input and first order output. For every patient, a logarithmic trend line $(y=a$ $\ln (\mathrm{x})+\mathrm{b})$ was calculated based on at least three plasma samples. The relative distribution volume (litres $/ \mathrm{kg})\left(\mathrm{V}_{\mathrm{d}}\right)$ and concentration at $\mathrm{t}=0\left(\mathrm{Cmax}_{0}\right)$ were calculated. The slope of the curve (slope $\left.=\left(\log C t_{2}-\log C t_{1}\right)\left(t_{2}-t_{1}\right)\right)$ was used to calculate the time constant $\mathrm{K}$ (slope $\times 2.303)$, elimination half life $(0.693 / K)\left(t_{1 / 2}\right)$, and total clearance $\left(K \times V_{d}\right)\left(C_{t}\right)$. Results are expressed as mean (SD) and range.

Student's $t$ test (normal distribution) or the Wilcoxon test was used to compare clinical and pharmacokinetic findings in preterm $(<37$ weeks GA) and term ( $\geqslant 37$ weeks GA) infants. Linear regression analysis of the effect of GA and birth weight on $t_{1 / 2}$ were calculated (MedCalc; Medi Software, Mariukerke, Belgium). The protocol was approved by the local ethics committee (Gasthuisberg, Leuven, Belgium), and infants were only included after written informed consent had been obtained from the parents.

\section{RESULTS}

Thirty neonates of variable GA were included in this singledose study. Fifteen received the $20 \mathrm{mg}$ ( $10 \mathrm{mg}$ paracetamol)/ $\mathrm{kg}$ dose, and the remaining 15 received a $40 \mathrm{mg}(20 \mathrm{mg}$ paracetamol)/kg dose. Table 1 summarises the clinical characteristics. The overall mean (SD) birth weight was 2111 (1094) g, and GA at inclusion was 33.8 (3.9) weeks. Postnatal age at inclusion was 12.7 (6.4) hours. Ten infants had a GA of $\geqslant 37$ weeks. Twenty infants were preterm $(<37$ weeks GA), 10 of whom were younger then 32 weeks GA. Twenty six infants received respiratory support, 16 of whom $(53 \%)$ were ventilated. Fifteen $(50 \%)$ received other analgesics in the first 24 hours of life.

In total, 213 blood samples were collected and analysed. Figure 1 gives the results for all the plasma samples; great variability can be observed.

Table 2 summarises the pharmacokinetic characteristics. No significant difference in relative $\mathrm{V}_{\mathrm{d}}$ (litres $/ \mathrm{kg}$ ) between preterm and term infants was found. $t_{1 / 2}$ and $C_{t}$ were significantly (both $\mathrm{p}<0.05$ ) different between preterm and term infants. Mean $t_{1 / 2}$ was 277 minutes in preterm infants and 172 minutes in term infants. Mean $\mathrm{CL}_{\mathrm{t}}$ was significantly lower in preterm than term infants $(0.116 v 0.170$ litre $/ \mathrm{kg} / \mathrm{h})$ In infants of $<32$ weeks GA, mean $t_{1 / 2}$ was 290 minutes, whereas in more mature infants (32-36 weeks GA) it was 265 minutes. Correlation of GA with $t_{1 / 2}(r=-0.46)$ was stronger than birth weight with $t_{1 / 2}(r=-0.39)$. Figure 2 shows linear regression analysis of the effect of GA on $t_{1 / 2}$ with $95 \%$ confidence intervals. We found no difference in $t_{1 / 2}$ or other clinical characteristics (birth weight, GA) between preterms $(<35$ weeks GA) who received $(\mathrm{n}=13)$ and preterms who did not receive $(\mathrm{n}=6)$ prenatal steroids (betamethasone) for lung maturation. Neither did we find any sex related differences.

\begin{tabular}{|c|c|c|}
\hline & Term & Preterm \\
\hline \multicolumn{3}{|l|}{ Birth weight (g) } \\
\hline Mean & $3323(538)$ & 1456 (592) \\
\hline Range & $1980-4000$ & $505-2440$ \\
\hline \multicolumn{3}{|l|}{ Gestational age (weeks) } \\
\hline Mean & $38.5(1.2)$ & $31.4(2.5)$ \\
\hline Range & $37-40$ & $27-35$ \\
\hline \multicolumn{3}{|l|}{ Maternal complications } \\
\hline Pre-eclampsia/HELLP & 3 & 4 \\
\hline Solutio placentae & 1 & 2 \\
\hline Other medical conditions & 0 & 2 \\
\hline Caesarean section & 2 & 12 \\
\hline \multicolumn{3}{|l|}{ Diagnosis } \\
\hline Respiratory distress & - & 9 \\
\hline Wet lung disease & 5 & - \\
\hline Meconium aspiration & 2 & - \\
\hline Pneumothorax & 1 & - \\
\hline Congenital heart disease & 1 & - \\
\hline Surgical conditions & 1 & 2 \\
\hline Prematurity & - & 9 \\
\hline \multicolumn{3}{|l|}{ Ventilation } \\
\hline $\mathrm{CV} / \mathrm{HFO}$ & 8 & 8 \\
\hline Nasal CPAP & - & 10 \\
\hline Prenatal betamethasone & - & 13 \\
\hline \multicolumn{3}{|c|}{$\begin{array}{l}\text { Results are reported as mean (SD) and range or by absolute } \\
\text { numbers in term ( } 37-41 \text { weeks) and preterm ( }<37 \text { weeks) } \\
\text { infants. Three infants received surgery on the first day of life } \\
\text { (oesophageal atresia). } \\
\text { HELLP, Haemolysis, elevated liver functions, low platelets; } \\
\text { CV, conventional ventilation; HFO, high frequency } \\
\text { oscillation; CPAP, continuous positive airway pressure. }\end{array}$} \\
\hline
\end{tabular}

As this is a single-dose study, other analgesics were allowed. Half of the infants received at least one other analgesic (fentanyl (11), tramadol (6), ibuprofen-lysine (1)) during the first 24 hours based on the standardised evaluation by pain score (Leuven neonatal pain scale). Level 1 pain (pain scale $<4$ ) was documented in 26/30 infants in the hours before paracetamol administration, in 30/30 infants during the period when a therapeutic level $(>5 \mathrm{mg} / \mathrm{l})$ of paracetamol had been reached, and in 24/30 infants afterwards. If we consider only infants $(n=15)$ who did not receive any analgesic besides paracetamol in the first 24 hours, level 1 analgesia was documented in 14/15 infants before administration, in 15/15 infants in the period when a therapeutic level had been reached, and in 12/15 infants after this period.

\section{DISCUSSION}

The serum half life was 277 (143) minutes in preterm infants and $172(59)$ minutes in term infants $(\mathrm{p}<0.05)$. Clearance was $0.116(0.08)$ litre $/ \mathrm{kg} / \mathrm{h}$ in preterm infants and 0.170 (0.06) litre $/ \mathrm{kg} / \mathrm{h}$ in term infants $(\mathrm{p}<0.05)$. The pharmacokinetics and pharmacodynamics of propacetamol are well documented in adults and children, but there is only one study on its pharmacokinetics in infants younger than 1 year ( $\mathrm{n}=12$, of which five were $<10$ postnatal days), and there are no data on propacetamol in preterm neonates. The pharmacokinetics of propacetamol in this study were compared with the pharmacokinetics of paracetamol and propacetamol in other cohorts described in the literature.

\section{Term neonates}

Our findings in term infants are in line with the single study on intravenous propacetamol..$^{10}$ Autret et al documented the pharmacokinetics in 12 infants, five of whom were less than 10 days old. The serum half life in these five neonates was 210 (30) minutes, $\mathrm{CL}_{\mathrm{t}}$ was 0.149 (0.067) litre $/ \mathrm{kg} / \mathrm{h}$, and $\mathrm{V}_{\mathrm{d}}$ was $0.7(0.2)$ (table 3). Pharmacokinetics after rectal 

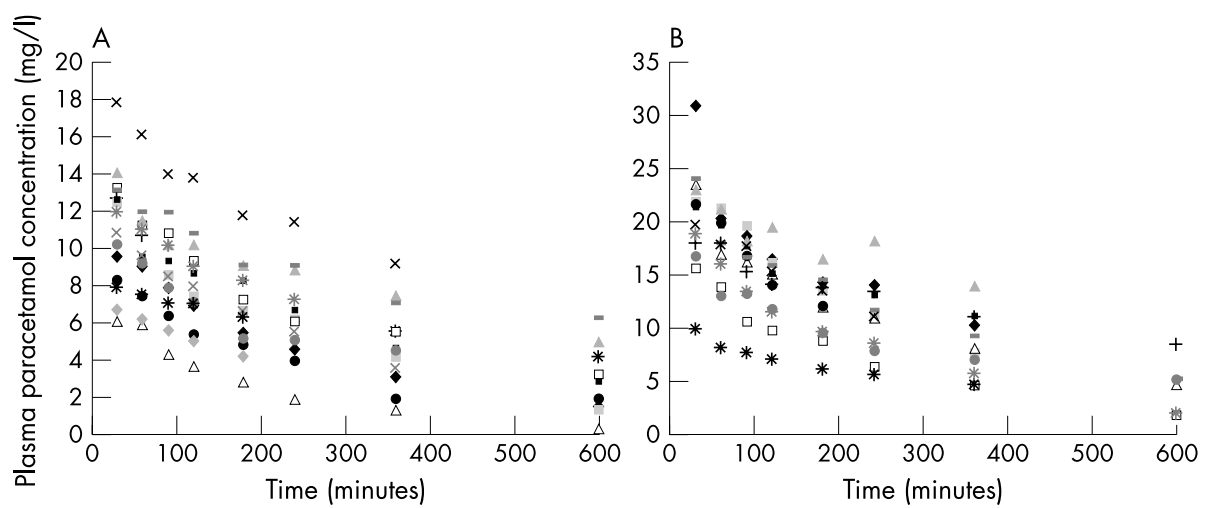

Figure 1 Plasma levels of paracetamol in all infants $(\mathrm{n}=213)$ after a single intravenous administration of $20 \mathrm{mg} / \mathrm{kg}(A)$ or $40 \mathrm{mg} / \mathrm{kg}(\mathrm{B})$ of propacetamol.

administration of paracetamol in term neonates were studied by Van Lingen et $a l^{11}$ and Hopkins et al. ${ }^{19}$ Van Lingen et al found a $t_{1 / 2}$ of $162(84)$ minutes $(\mathrm{n}=10)$, and Hopkins et al found a $t_{1 / 2}$ of 228 minutes $(n=9)$. There are no studies on the pharmacokinetics of paracetamol after nasogastric administration in the first day of life. Studies in neonates by Hopkins et al $^{19}(\mathrm{n}=3)$ and Anderson et $a l^{9}(\mathrm{n}=16)$ after nasogastric administration found a serum $t_{1 / 2}$ of 168 minutes and 576 minutes respectively. Co-administration of opioids and its effect on gastric motility may, at least partially, explain these differences. There is a recent report on unintentional intramuscular administration of propacetamol in one term neonate; in that single case, the calculated serum half life was 210 minutes. $^{20}$

\section{Preterm infants}

Mean $t_{1 / 2}(<37$ weeks $\mathrm{GA} ; \mathrm{n}=20)$ and $\mathrm{CL}_{\mathrm{t}}$ after a single dose were 277 minutes and $0.116 \mathrm{litre} / \mathrm{kg} / \mathrm{h}$ in preterm infants, and the relative $V_{d}$ was 0.61 litre $/ \mathrm{kg}$. In infants of $<32$ weeks GA, mean $t_{1 / 2}$ was 290 minutes, and in more mature infants (32-36 weeks GA), it was 265 minutes. Data on the pharmacokinetics of paracetamol in preterm neonates are only available after rectal administration. Van Lingen et $a l^{11}$ studied pharmacokinetics after rectal administration of paracetamol in 28 preterm neonates in the first day of life (28-36 weeks GA). $t_{1 / 2}$ was 660 (342) minutes in the 2832 week GA group and 450 (240) minutes in the 32-36 week GA group. Mean maximal concentration was 12.5 and $7.5 \mathrm{mg} / \mathrm{l}$, and mean time to reach maximal concentration was 234 and 306 minutes (28-32 and 32-36 weeks). Lin et $a l^{12}$ found a mean (SD) maximum concentration of 8.38 (3.9) $\mathrm{mg} / \mathrm{l}$ and a mean (SD) time to reach maximum concentration of $78(40)$ minutes after rectal administration

Table 2 Pharmacokinetics of propacetamol in preterm ( $<37$ weeks) and term (37-41 weeks) infants

\begin{tabular}{lll}
\hline & Preterm & Term \\
\hline $\begin{array}{l}\text { Number of infants } \\
\text { Relative } V_{d} \text { (litre/kg) }\end{array}$ & 20 & 10 \\
$\begin{array}{l}\text { Mean } \\
\text { Range }\end{array}$ & $0.61(0.15)$ & $0.64(0.25)$ \\
$\mathrm{t}_{1 / 2}(\mathrm{~min})$ & $0.44-1$ & $0.46-1.3$ \\
$\quad$ Mean & $277(143)$ & $172(59)$ \\
$\quad$ Range & $87-680$ & $100-269$ \\
$\begin{array}{c}\text { Clearance (litre } / \mathrm{kg} / \mathrm{h}) \\
\text { Mean }\end{array}$ & $0.116(0.08)$ & $0.170(0.06)$ \\
Range & $0.004-0.24$ & $0.08-0.29$ \\
\hline & & \\
\hline
\end{tabular}

of $20 \mathrm{mg} / \mathrm{kg}$ in five preterm neonates. ${ }^{12}$ These findings are formulation specific, but may be relevant in clinical care as therapeutic drug concentration after intravenous administration will be reached sooner.

Combining pharmacokinetic data in term and preterm neonates in our population with the findings of Autret et al ${ }^{10}$ in neonates and infants, a maturational trend during the first year of life is observed (table 3 ). This is in line with the developmental pharmacokinetics described after oral or rectal administration of paracetamol. ${ }^{7}{ }^{10}$

Although we observed a maturational trend in the pharmacokinetics of paracetamol after intravenous administration, overall correlation $(r=-0.46)$ between GA and $t_{1 / 2}$ is still weak. In contrast with rectal and oral administration, differences in bioavailability (venous rectal drainage, gastrointestinal motility) cannot explain this variability. Further study of other variables potentially responsible for this variability is needed. Prenatal administration of betamethasone for lung maturation had no maturational effect on $t_{1 / 2}$ in this study. We did not find any sex related differences, in contrast with the findings reported after rectal administration. ${ }^{11}$

Pharmacodynamic data suggest an analgesic effect of intravenous paracetamol in this population. The design of this study (not blinded, other analgesics allowed) does not allow us to draw conclusions other than that multiple dose administration of intravenous paracetamol should be adjusted for GA. Based on the longer $t_{1 / 2}$ in preterm infants, either the interval should be longer or the dose should be lower, in line with reported regimens for rectal and oral administration. $^{7911}$

Because of the major interindividual variability of the pharmokinetics in preterm infants, we believe it is too early to make any multiple dose recommendations. In term

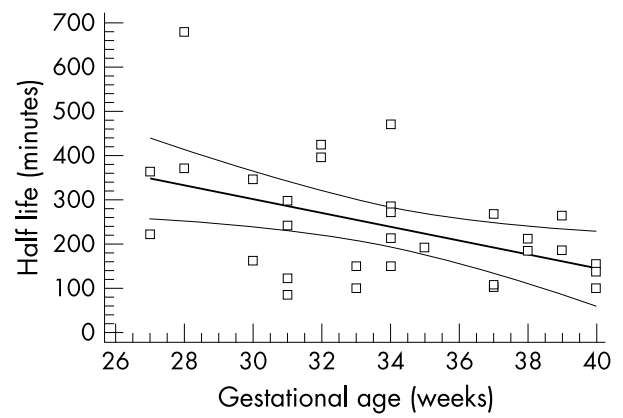

Figure 2 Linear regression analysis (with 95\% confidence intervals) of the effect of gestational age on serum half life $(r=-0.46)$. 
Table 3 Maturational trend (mean) of serum half life $\left(t_{1 / 2}\right)$ and relative distribution volume (relative $V_{d}$ ) in the first year of life after intravenous administration of propacetamol, based on this population* and on the study of Autret et al. ${ }^{10} \dagger$

\begin{tabular}{llllll}
\hline & $\begin{array}{l}\text { Preterm } \\
(<\mathbf{3 2} \text { weeks) }\end{array}$ & $\begin{array}{l}\text { Preterm } \\
(\mathbf{3 2 - 3 6} \text { weeks })^{*}\end{array}$ & $\begin{array}{l}\text { Term } \\
(\text { day } \mathbf{~})^{*}\end{array}$ & $\begin{array}{l}\text { Term } \\
(<\mathbf{1 0} \text { days }) \dagger\end{array}$ & $\begin{array}{l}<\mathbf{1} \text { year } \\
(\mathbf{1 0}-\mathbf{3 6 5} \text { days }) \dagger\end{array}$ \\
\hline Number infants & 10 & 10 & 10 & 5 & 7 \\
$t_{1 / 2}(\mathbf{m i n})$ & 290 & 265 & 172 & 210 & 126 \\
Relative $V_{d}$ (litre $\left./ \mathrm{kg}\right)$ & 0.66 & 0.56 & 0.61 & 0.7 & 0.9 \\
\hline
\end{tabular}

infants, a loading dose of $30 \mathrm{mg} / \mathrm{kg}$ propacetamol—that is $15 \mathrm{mg}$ paracetamol-followed by $20 \mathrm{mg} / \mathrm{kg}$ every six hours could be considered. As accumulation may still occur in the individual neonate, it is safest and feasible to determine plasma concentrations until additional data are available.

\section{ACKNOWLEDGEMENTS}

GN is supported by the Fund for Scientific Research-Flanders (Belgium) (Clinical Doctor Grant A615-cm.D11.354).

\section{Authors' affiliations}

K Allegaert, A Debeer, C Vanhole, H Devlieger, Neonatal Intensive Care Unit, Department of Paediatrics, University Hospitals,

Gasthuisberg, Herestraat 49, Leuven, Belgium

K Allegaert, C D Van der Marel, D Tibboel, Department of Paediatric Surgery, Sophia's Children's Hospital, Rotterdam, the Netherlands M A L Pluim, Department of Pharmacy, Sophia's Children's Hospital R A Van Lingen, Department of Paediatrics, the Isala Clinics, Zwolle, the Netherlands

These results were partially presented at the biannual congress of the European Society of Developmental Pharmacology (ESDP) Liège, 25-28 October 2002.

\section{REFERENCES}

1 Anand KJ, Phil D, Hickey PR. Pain and its effects in the human neonate and fetus. N Engl J Med 1987;317:1321-6.

2 Ambalavanan N, Carlo WA. Analgesia for ventilated neonates: where do we stand? J Pediatr 1999; 135:403-5.

3 Kennedy KA, Tyson JE. Narcotic analgesia for ventilated newborns: are placebo-controlled trials ethical and necessary? J Pediatr 1999;134:127-9.

4 Anand KJ, Barton BA, Mclntosch N, et al. Analgesia and sedation in preterm neonates who require ventilatory support. Results from the NOPAIN trial: neonatal outcome and prolonged analgesia in neonates. Arch Pediatr Adolesc Med 1999;153:331-8.
5 Anand KJ. International evidence-based group for neonatal pain. Consensus statement for the prevention and management of pain in the newborn. Arch Pediatr Adolesc Med 2001;155:173-80

6 Barr J, Brenner-Zada G, Heiman E, et al. Unlicensed and off-label medication use in a neonatal intensive care unit: a prospective study. Am J Perinatol 2002: 19:67-72.

7 Arana A, Morton NS, Hansen TG. Treatment with paracetamol in infants. Acta Anaesthesiol Scand 2001;45:20-9.

8 Anderson BJ. What we don't know about paracetamol in children. Paediatr Anaesth 1998:8:451-60.

9 Anderson BJ, Van Lingen RA, Hansen TG, et al. Acetaminophen developmental pharmacokinetics in premature neonates and infants. Anesthesiology 2002;96:1336-45.

10 Autret E, Dutertre JP, Breteau M, et al. Pharmacokinetics of paracetamol in the neonate and infant after administration of propacetamol chlorhydrate. Dev Pharmacol Ther 1993;20:129-34

11 Van Lingen RA, Deinum HT, Quak JM, et al. Pharmacokinetics and metabolism of rectally administered paracetamol in preterm infants. Arch Dis Child Fetal Neonatal Ed 1999;80:F59-63.

12 Lin YC, Sussman HH, Benitz WE. Plasma concentrations after rectal administration of acetaminophen in preterm neonates. Paediatr Anaesth 1997:7:457-9.

13 Van Lingen RA, Deinum HT, Quak CM, et al. Multiple-dose pharmacokinetics of rectally administered acetaminophen in term infants. Clin Pharmacol Ther 1999;66:509-15.

14 Tenenbein $M$. Why young children are resistant to acetaminophen poisoning? J Pediatr 2000;137:891-2.

15 De Peyster A, Willis WO, Liebhaber M. Cholinesterase activity in pregnant women and newborns. J Toxicol Clin Toxicol 1994;32:683-96.

16 Allegaert K, Tison D, De Jonge A, et al. Measures to assess and to treat: the development of a neonatal pain scale. Tijdschr Geneesk 2002;58:155-61.

17 Allegaert K, Tibboel D, Naulaers G, et al. Systematic evaluation of pain in neonates: effect on the number of intravenous analgesics prescribed. Eur J Clin Pharmacol 2003;59:87-90.

18 Depre $M$, van Hecken A, Verbesselt R, et al. Tolerance and pharmacokinetics of propacetamol, a paracetamol formulation for intravenous use. Fundam Clin Pharmacol 1992;6:259-62.

19 Hopkins CS, Underhill S, Booker PD. Pharmacokinetics of paracetamol after cardiac surgery. Arch Dis Child 1990;65:971-6.

20 Nolent P. Intramuscular injection of propacetamol in a neonate. Arch Dis Child Fetal Neonatal Ed 2002;87:F155.

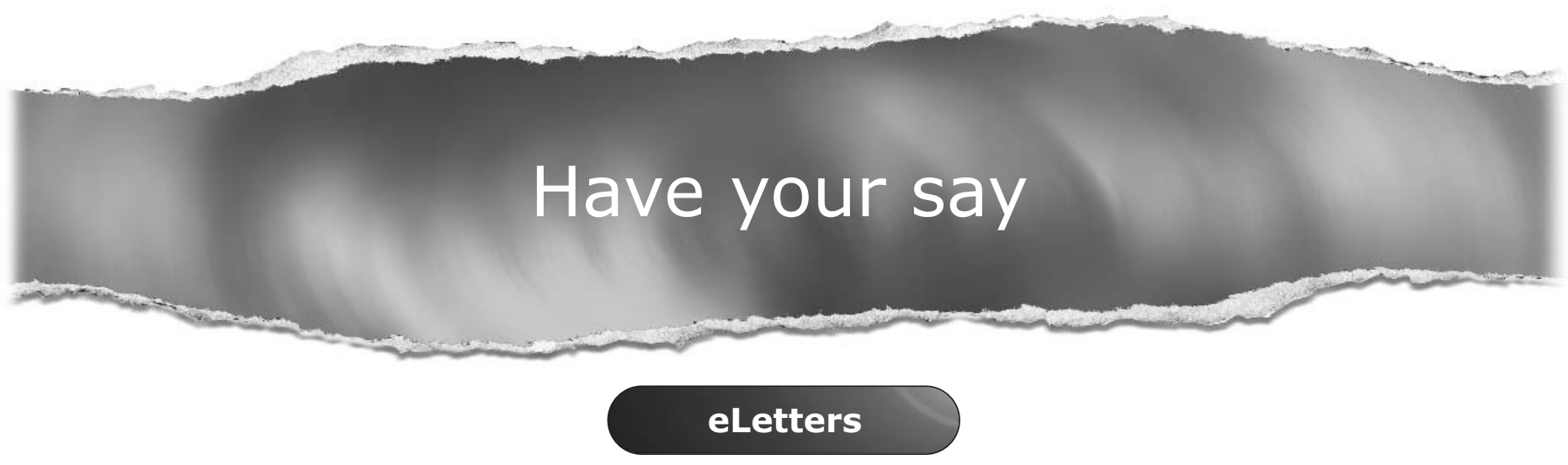

If you wish to comment on any article published in Archives of Disease in Childhood you can send an eLetter using the eLetters link at the beginning of each article. Your response will be posted on Archives of Disease in Childhood online within a few days of receipt (subject to editorial screening).

\section{www.archdischild.com}

